\title{
A study on relationship between social capital and sustainable development
}

\author{
Shabnam Fotovvat ${ }^{a^{*}}$, karam Safari $^{\mathrm{a}}$, Karamollah Zayyari $^{\mathrm{b}}$ and Somayeh boostani ${ }^{\mathrm{c}}$
}

${ }^{a}$ Department of Management, University of Tehran Aras International Campus, Tehran, Iran

${ }^{b}$ PhD in Geography and City Planning

${ }^{c}$ Masters in Financial Management, University of Abhar, Abhar, Iran

CHRON I C LE ABSTRACT

Article history:

Received March 202014

Accepted 28 July 2014

Available online

August 32014

Keywords:

Social capital

Sustainable development

Salmas

\begin{abstract}
This paper presents an empirical investigation to study the relationship between social capital components, social trust, social cohesion, social participation and social security, and sustainable development in city of Salmas, Iran. The study designs a questionnaire in Likert scale, distributes it among 384 randomly selected people who live in this city. Cronbach alpha has been calculated as 0.92 , which is well above the minimum acceptable level. Using regression technique, the study has determined a positive and meaningful relationship between three components of social capital and sustainable development including social cohesion, social participation and social security. However, the study does not confirm the relationship between social trust and sustainable development.
\end{abstract}

(C) 2014 Growing Science Ltd. All rights reserved.

\section{Introduction}

Sustainable development is one of the requirements for economic development in any society and there is a need to determine important factors influencing it (Woolcock, 1998; Wakefield \& Poland, 2005; Skinner et al., 2008). There are literally various attempts to detect influential factors. Lehtonen (2004), for instance, traced the evolution of social capital research as it pertains to economic development and identified four distinct methods: communitarian, networks, institutional, and synergy. The measurement of sustainable development is not without significant difficulties, yet this could not detract from the positive advances made in this direction. Pearce and Atkinson (1993) presented one form that a "weak" sustainability indicator can take. According to Rankin (2002), policy makers increasingly depend on theories of social capital to fashion development interventions, which mobilize local social networks in the alleviation of poverty. The potential of such theory lies in its recognition of the social dimensions of economic growth. According to Labonte (1999), Social capital is a useful concept for practitioners, researchers and policy makers in bring the missing 'social' into economic and fiscal policy debates. However, its implementation should be approached cautiously as a construct of potential strategic value.

*Corresponding author.

E-mail addresses: Shabnamfotovvat@yahoo.com (S. Fotovvat) 
Labonne and Chase (2011) explored the social capital effects of a community-driven development project in the Philippines in which communities competed for block grants for infrastructure investment. The survey applied a unique panel data set of about 2100 households, aggregated at the village-level, collected in 66 treatment and 69 comparison communities. They provided both difference-in-differences and propensity score matching estimates and reported that the project increased participation in village assemblies and the frequency with which local officials meet with residents and had a negative effect on collective action. There was also more limited evidence of a positive effect of the project on bridging trust and of a negative effect on group membership.

\section{The proposed study}

This paper presents an empirical investigation to study the relationship between social capital components, Social trust, Social Cohesion, Social participation and Social security, and sustainable development in city of Salmas, Iran. Fig. 1 demonstrates the structure of the proposed study.

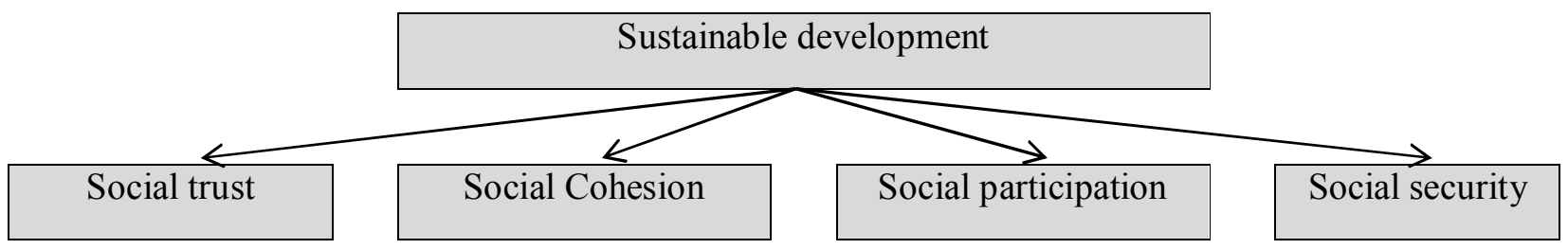

Fig. 1. The proposed study

The study designs a questionnaire in Likert scale with 23 questions in which four questions are associated with social trust, four questions are devoted to measure social cohesion, four questions are related to social partnership and five questions are associated with social security. In addition, 6 questions are associated with sustainable development. Cronbach alpha for Social trust, Social Cohesion, Social participation and Social security, and sustainable development are calculated as $0.81,0.85,0.86,0.95$ and 0.95 , respectively. These are well above the minimum acceptable level of 0.7 and they verify the overall survey. There were 6000 residence who were living in north region of the city of Salmas where the survey has been accomplished and the sample size is calculated as follows,

$$
n=\frac{N \times z_{\alpha / 2}^{2} \times p \times q}{\varepsilon^{2} \times(N-1)+z_{\alpha / 2}^{2} \times p \times q},
$$

where $N$ is the population size, $p=1-q$ represents the yes/no categories, $z_{\alpha / 2}$ is CDF of normal distribution and finally $\varepsilon$ is the error term. Since we have $p=0.5, z_{\alpha / 2}=1.96$ and $N=6000$, the number of sample size is calculated as $n=384$. Kolmogorov-Smirnov has been used to verify whether the data were normally distributed or not. Table 1 demonstrates the summary of our findings.

Table 1

The summary of Kolmogorov-Smirnov test

\begin{tabular}{lccccc}
\hline & Trust & Cohesion & Partnership & Security & Sustainable development \\
\hline $\mathrm{N}$ & 360 & 360 & 360 & 360 & 360 \\
Mean & 2.88 & 3.06 & 3.31 & 3.13 & 33.06 \\
Std. dev. & 1.07 & 1.099 & 0.97 & 0.98 & 1 \\
Absolute & 0.097 & 0.132 & 0.55 & 0.066 & 0.061 \\
Positive & 0.077 & 0.132 & 0.107 & 0.066 & 0.047 \\
Negative & -0.097 & -0.079 & 0.08 & -0.05 & -0.061 \\
\hline Kolmogorov-Smirnov Z & 1.48 & -0.107 & 0.681 & 0.661 \\
\multicolumn{2}{l}{ Asymp. Sig. (2-tailed) } & 0.054 & 1.183 & 0.48 & 0.775 \\
\hline
\end{tabular}


As we can observe from the results of Table 1, all components of the survey are normally distributed when the level of significance is five percent. Therefore, we can use parametric tests to verify the hypotheses of the survey. Fig. 2 demonstrates personal characteristics of the participants.

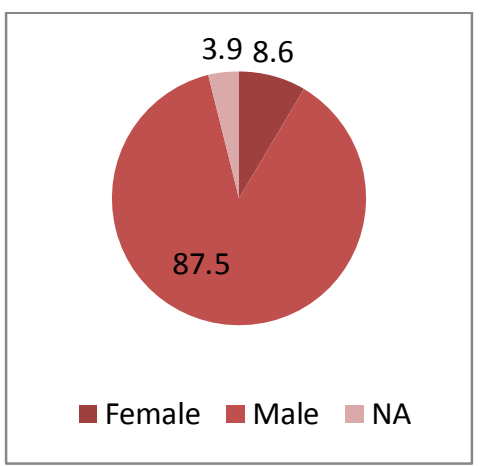

Gender

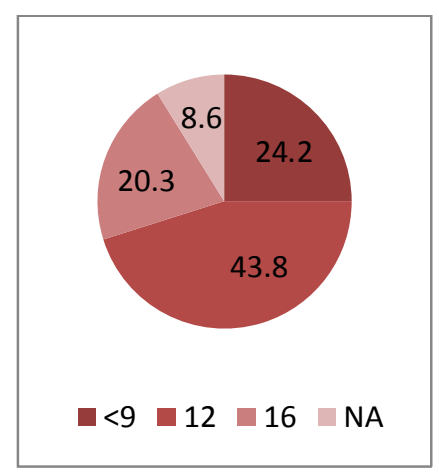

Years of education

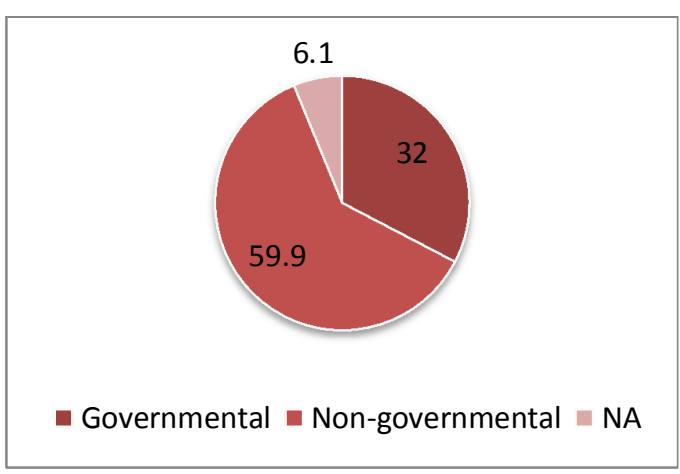

Job title

Fig. 2. Personal characteristics of the participants

As we can observe from the results of Fig. 2, most participants of our survey were male and only $28.9 \%$ of them hold university education. In addition, nearly $60 \%$ of them had non-governmental jobs.

\section{The results}

In this section, we present details of the implementation of the regression analysis. The study uses four simple regression functions, where social development is the dependent variable and four components of sustainable development are independent variables. Table 2 demonstrates the summary of our findings.

Table 2

The summary of regression analysis

\begin{tabular}{llcccc}
\hline Variable & Description & \multicolumn{2}{c}{ Coefficient } & t-value & Sig. \\
\hline Dependent & Sustainable development & Intercept & 3.18 & 8.17 & 0.000 \\
Independent & Social trust & Slop & -1.9 & -0.15 & 0.43 \\
\hline Dependent & Sustainable development & Intercept & 1.55 & 3.19 & 0.003 \\
Independent & Social cohesion & Slop & 0.142 & 3.42 & 0.027 \\
\hline Dependent & Sustainable development & Intercept & 3.79 & 13.65 & 0.000 \\
Independent & Social trust & Slop & 0.22 & -2.05 & 0.001 \\
\hline Dependent & Sustainable development & Intercept & 1.44 & 1.6 & 0.12 \\
Independent & Social partnership & Slop & 0.39 & 1.97 & 0.06 \\
\hline
\end{tabular}

As we can observe from the results of Table 2, there is no meaningful relationship between social trust and sustainable development. However, there are positive and meaningful relationships between other components of social capital including social cohesion, social trust and social partnership with sustainable development.

\section{Conclusion}

In this paper, we have presented an empirical investigation to study the relationship between social capital and sustainable development in one of Iranian cities located in north-west of the country. The results of our survey have indicated that there were positive and meaningful relationships between three components of social capital and sustainable development when the level of significance was 
five percent. The strongest relationship belonged to social partnership $(\beta=0.39$, Sig. $=0.06)$ followed by social trust $(\beta=0.22$, Sig. $=0.001)$ and Social cohesion $(\beta=0.142$, Sig. $=0.027)$.

\section{Acknowledgment}

The authors would like to thank anonymous referees for constructive comments on earlier version of this paper.

\section{References}

Labonte, R. (1999). Social capital and community development: practitioner emptor. Australian and New Zealand Journal of Public Health, 23(4), 430-433.

Lehtonen, M. (2004). The environmental-social interface of sustainable development: capabilities, social capital, institutions. Ecological economics, 49(2), 199-214.

Labonne, J., \& Chase, R. S. (2011). Do community-driven development projects enhance social capital? Evidence from the Philippines. Journal of Development Economics, 96(2), 348-358.

Pearce, D. W., \& Atkinson, G. D. (1993). Capital theory and the measurement of sustainable development: an indicator of "weak" sustainability. Ecological economics, 8(2), 103-108.

Rankin, K. N. (2002). Social capital, microfinance, and the politics of development. Feminist economics, 8(1), 1-24.

Skinner, J., Zakus, D. H., \& Cowell, J. (2008). Development through sport: Building social capital in disadvantaged communities. Sport management review, 11(3), 253-275.

Wakefield, S. E., \& Poland, B. (2005). Family, friend or foe? Critical reflections on the relevance and role of social capital in health promotion and community development. Social Science \& Medicine, 60(12), 2819-2832.

Woolcock, M. (1998). Social capital and economic development: Toward a theoretical synthesis and policy framework. Theory and Society, 27(2), 151-208. 